\title{
A Simplified Algorithm for the Diagnosis, Treatment, and Management of COPD in Routine Primary Care Practice
}

This article was published in the following Dove Press journal: International Journal of Chronic Obstructive Pulmonary Disease

\author{
Carlos Cabrera López' \\ Enrique Mascarós $\mathbb{1 D}^{2}$ \\ Angel Azpeitia ${ }^{3}$ \\ Elena Villarrubia ${ }^{4}$ \\ 'Hospital Universitario de Gran Canaria \\ Dr. Negrín, Las Palmas de Gran Canaria, \\ Spain; ${ }^{2}$ Consultorio Auxiliar Arquitecto \\ Tolsá, Valencia, Spain; ${ }^{3}$ Esteve \\ Pharmaceuticals, SA, Barcelona, Spain; \\ ${ }^{4}$ Health Outcomes Research \\ Department, Advanced Outcomes \\ Research, SL. Barcelona, Spain
}

Background: Diagnostic and treatment strategies for chronic obstructive pulmonary disease (COPD) vary greatly. Despite international efforts to standardize the management of COPD, two-thirds of primary care patients are not diagnosed, treated, or managed according to current evidence-based guidelines, probably because of the difficulty of applying these in routine practice. The aim of this study was to develop a simplified algorithm for diagnosing, treating, and managing COPD in primary care whose consistency, scientific relevance, and applicability to routine clinical practice met approval bet $3 y$ family doctors (FDs) and pulmonologists.

Methods: The algorithm was developed in a series of sequential phases, consisting of a preliminary meeting among group coordinators to design the initial structure, an input meeting with FDs and pulmonologists to refine and validate the proposal, an algorithm design stage, and a Delphi survey in which FDs and pulmonologists evaluated and approved the final version. A target of $75 \%$ or more was established for each of the 20 items in the Delphi survey in the FDs group as well as the pulmonologists group. It was estimated that at least two Delphi rounds would be needed to reach consensus.

Results: In total, 118 physicians (75 FDs and 43 pulmonologists) participated in the Delphi process. Fourteen of the 20 items (70\%) were approved in the first round. In the second round (in which 74 FDs and 42 pulmonologists participated), the remaining six items, which had been reformulated based on feedback from the first round, were approved, together with an additional question on the face validity of the algorithm as a whole. Dyspnea was positioned as the main determinant of treatment decisions in the new algorithm.

Conclusion: According to the experts consulted, this new simplified algorithm for the diagnosis, treatment, and management of COPD in primary care is a clear, functional, and useful tool for routine practice and meets the requirements for the correct management of this condition.

Keywords: COPD, primary care, management, treatment, Delphi technique, consensus

\section{Introduction}

Approaches to the management of chronic obstructive pulmonary disease (COPD) vary greatly, particularly in primary care, where approximately two-thirds of patients with COPD are managed.,

A number of expert guidelines seeking to promote the standardized diagnosis, treatment, and management of COPD based on the available evidence have recently been published, such as the Global Initiative for Chronic Obstructive
Correspondence: Carlos Cabrera López Email ccablopn@gmail.com
International Journal of Chronic Obstructive Pulmonary Disease 2020:I5 3347-3355

3347 
Lung Disease (GOLD) 2020 Global Strategy for Prevention, Diagnosis, and Management of $\mathrm{COPD}^{3}$ and the Spanish GesEPOC (COPD management) guidelines. ${ }^{4}$ While these guidelines have been widely disseminated, few patients in Spain are managed according to their recommendations. ${ }^{1}$

Close adherence to COPD clinical practice guidelines in routine primary care settings is difficult for a number of reasons, including limited use or availability of spirometry, assessment of symptoms using different scales with varying dimensions, and the complexity of algorithms theoretically designed to facilitate the management of COPD. A number of groups have designed simplified algorithms based on the guideline recommendations to facilitate the structured, standardized treatment of COPD in both primary and specialist settings. ${ }^{5,6}$ The creators of these algorithms, however, did not seek broad consensus from practitioners involved in the care of patients with COPD, and such consensus is key to the successful management of any chronic disease. ${ }^{7}$ A simplified algorithm for managing COPD in primary care needs to be both useful and practical, and its content should be guided by input from clinicians involved in the daily care of these patients, whether family or community doctors (referred to hereafter as family doctors [FDs]) or pulmonologists.

The aim of this study was to create a simple algorithm for the management of COPD in primary care based on the available evidence on diagnosis, classification, treatment, and follow-up with the consensus and approval of FDs and pulmonologists involved in the care of patients with COPD.

\section{Methods}

The study was divided into four consecutive phases (Figure 1): 1) a preliminary study coordinator meeting, 2) an expert input session, 3) an algorithm design stage, and 4) a two-round Delphi process to evaluate and reach consensus on the proposed algorithm. In phases 2 and 4 were invited a random sample of FDs with no special interest in respiratory diseases and pulmonologists with broad experience in COPD management.

\section{Preliminary Meeting}

Prior to the input session, the study coordinators reviewed the literature to gather information from existing guidelines and recommendations on the diagnosis, treatment, and management of COPD. ${ }^{1,-4-6,8-27}$
During the preliminary meeting, the study coordinators assessed the strength of evidence for the actual guidelines recommendations and made any observations considered pertinent (Figure 2). With this information, they prepared and approved a working document for the input session with the FDs and pulmonologists.

\section{Input Session}

Nine FDs and eight pulmonologists were invited to participate in the input session. The sample was composed of a nationwide representative model of pulmonologists and FDs. The geographic location of the participants, as well as the expertise, was spread evenly. All the participants were working actively at the time. The purpose of this session was to determine the information that needed to be included in the simplified algorithm for managing COPD in primary care. The task of the FDs was a) to provide information on routine practice in the diagnosis, treatment, and management of COPD in primary care, and b) to approve the proposals and recommendations for the new algorithm in terms of their applicability to routine practice in this setting. The pulmonologists' task was to confirm that the proposals and recommendations met the requisites for the correct diagnosis, treatment, and management of COPD.

\section{Algorithm Design}

Using the feedback from the FDs and pulmonologists in the input session, a working group consisting of two technical-methodology experts, with wide expertise in the design of Delphi studies and in the field of methodology, and one clinical expert designed the draft algorithm, which was structured into two main blocks: "diagnosis" and "classification and treatment." Their proposal was reviewed by the coordinators and the FDs and pulmonologists from the input phase before being presented to the participants in the next stage, the Delphi process (Table 1).

\section{Delphi Process}

The fourth phase of the project (Figure 1) was a two-round Delphi process ${ }^{28}$ in which 118 physicians (75 FDs and 43 pulmonologists) were asked to evaluate the proposed algorithm.

The Delphi survey consisted of 20 questions: five related to the diagnosis section of the algorithm, 14 related to the treatment and follow-up section, and one on the general design. Consensus for each survey item 


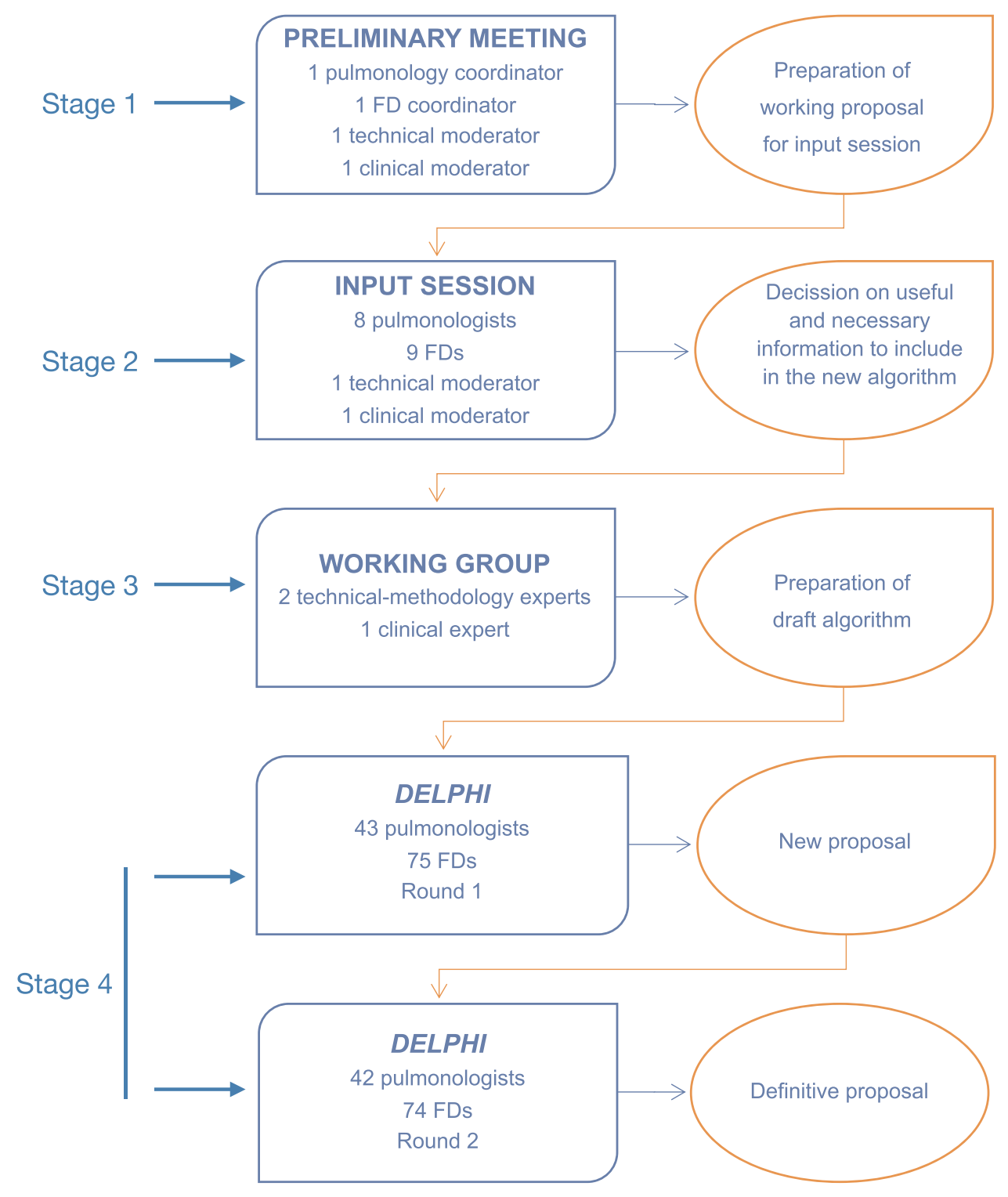

Figure I Flow chart of process.

was established as approval by at least $75 \%$ of the overall participants of FDs group as well as $75 \%$ or more of participants of the pulmonologists group. Items for which consensus was not reached in the first round were modified and presented again in a second round.

As this study did not include any patients, there was no need for approval of any ethic committee.

\section{Results}

The nine FDs and eight pulmonologists who participated in the input session reported that they followed guideline recommendations for both the diagnosis and treatment of COPD. They all used the Spanish GesEPOC guideline, ${ }^{4}$ but just a few of the FDs stated that they used the GOLD guideline. $^{3}$

In the input session, the main recommendations to be included in the algorithm were to include a post-bronchodilator spirometry to confirm suspected COPD, to consider other entities in the differential diagnosis before confirming a diagnosis of COPD, and to classify and treat COPD based on dyspnea grade, number and severity of exacerbations, and/or hospital admissions in the past year (Supplementary Appendix Table 1). 


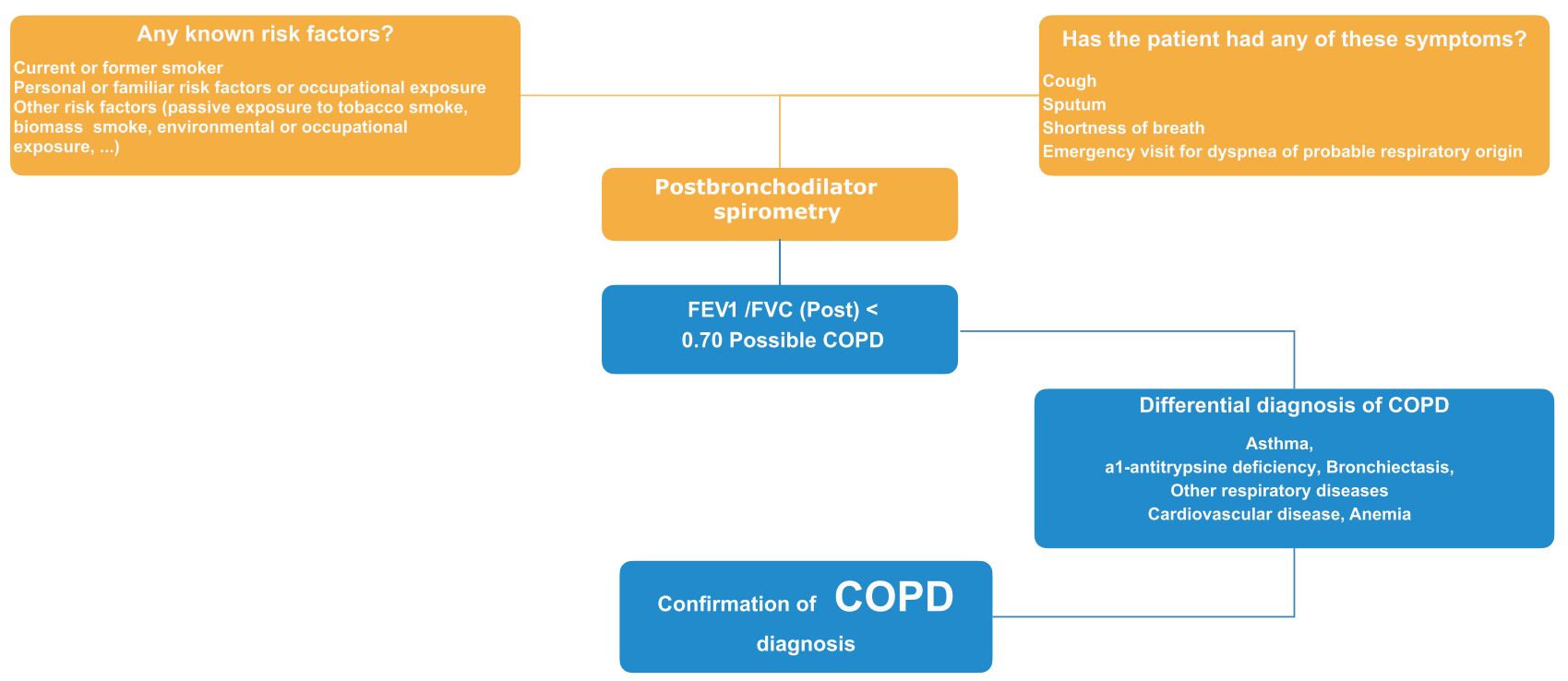

Figure 2 Final diagram of the diagnosis of COPD as proposed by the Delphi consensus.

In the first round of the Delphi process, consensus was reached for 14 of the 20 items $(70 \%)$ sent to the 75 FDs and 43 pulmonologists (Table 1). The six items for which consensus was not reached were reformulated based on the feedback given by the experts for further assessment in round 2 .

The second Delphi survey, thus, contained six questions (the six reformulated items from round 2) and was completed by 116 of the 118 physicians who had participated in the first round (74 FDs and 42 pulmonologists). Consensus was reached for all six items (Table 2). On analyzing the breakdown of responses by group, there was just one item on which consensus was not reached in both groups. The item in question was:

Do you think it is appropriate for a patient who is on multiple therapy to be monitored in primary care if he/she has stable COPD (no exacerbation and no increase in the level of dyspnea), and to be referred to a pulmonologist otherwise?; $87.8 \%$ of FDs thought that this recommendation was appropriate versus $66.7 \%$ of the pulmonologists. However, because the combined level of consensus was $80 \%$, this specific recommendation was included in the final algorithm as an exception.

To confirm the face validity of the algorithm as a whole, the participants in the Delphi process were asked if they thought that the algorithm was clear and practical for use in routine primary care practice; $94.6 \%$ of the FDs and $85.7 \%$ of the pulmonologists said "yes".
The new simplified algorithm for the diagnosis (Figure 2), treatment, and management of COPD in primary care (Figure 3) was thus approved by consensus by all participating physicians.

\section{Discussion}

The discussions that took place during the preparatory and input sessions with the coordinators and experts revealed the impracticality of using COPD clinical guidelines in routine primary care practice, highlighting the need for a new, simplified algorithm more suited to the reality of this setting.

To create such an algorithm, we sought input and consensus from FDs and pulmonologists with extensive experience in caring for patients with COPD to ensure that the new tool would meet the requirements needed for the correct diagnosis, treatment, and management of COPD in routine clinical practice and be practical and useful.

The development of the project in phases (Figure 1) enabled us to progressively introduce key aspects and criteria associated with the practicalities of treating a patient with COPD in primary care.

Consensus was reached for $70 \%$ of the items proposed in the first round of the Delphi process. This high level of agreement is probably due to the work done in the previous phases, as the preparatory work done in Phase 1 and the feedback from the input session with the FDs and pulmonologists in Phase 2 provided key insights into the 
Table I Results of the First Round of the Delphi Process

\begin{tabular}{|c|c|c|c|c|}
\hline Question & $\begin{array}{l}\text { No. }(\%) \text { in } \\
\text { Agreement } \\
\text { (FDs) }\end{array}$ & $\begin{array}{l}\text { No. (\%) in } \\
\text { Agreement } \\
\text { (Pulmonologists) }\end{array}$ & $\begin{array}{l}\text { No. }(\%) \text { in } \\
\text { Agreement } \\
\text { (Overall) }\end{array}$ & $\begin{array}{l}\text { Decision } \\
\text { Taken }\end{array}$ \\
\hline \multicolumn{5}{|l|}{ Diagnosis } \\
\hline $\begin{array}{l}D_{x} I \\
\text { Do you think that the PATIENT EVALUATION section of the algorithm } \\
\text { adequately covers the main SYMPTOMS that should raise suspicion of } \\
\text { COPD? }\end{array}$ & 71 (94.7\%) & $38(88.4 \%)$ & 109 (92.4\%) & Consensus \\
\hline $\begin{array}{l}D_{x} 2 \\
\text { Do you think that the PATIENT EVALUATION section of the algorithm } \\
\text { adequately covers the main RISK FACTORS that should raise suspicion of } \\
\text { COPD? }\end{array}$ & $54(72 \%)$ & $30(69.8 \%)$ & $84(71.2 \%)$ & $\begin{array}{l}\text { Pass to } \\
\text { round } 2\end{array}$ \\
\hline $\begin{array}{l}D_{\times} 3 \\
\text { Do you think that the algorithm adequately covers the main entities that } \\
\text { should be included in the DIFFERENTIAL DIAGNOSIS to rule out COPD? }\end{array}$ & 70 (93.3\%) & $32(74.4 \%)$ & $102(86,4 \%)$ & $\begin{array}{l}\text { Pass to } \\
\text { round } 2\end{array}$ \\
\hline $\begin{array}{l}D_{\times} 4 \\
\text { Do you think that the RECOMMENDATIONS for patients with newly } \\
\text { diagnosed COPD are appropriate? }\end{array}$ & $63(85.2 \%)$ & 37 (86\%) & $100(84.7 \%)$ & Consensus \\
\hline $\begin{array}{l}D_{x} 5 \\
\text { Overall, do you think that the design of the DIAGNOSIS section of the } \\
\text { algorithm is clear and practical for routine management of COPD in primary } \\
\text { care? }\end{array}$ & 69 (92\%) & $38(88.4 \%)$ & 107 (90.7\%) & Consensus \\
\hline \multicolumn{5}{|l|}{ Classification and treatment } \\
\hline $\begin{array}{l}T_{x} I \\
\text { Do you think that the proposed classification system COVERS ALL PROFILES } \\
\text { of patients with COPD? }\end{array}$ & $67(89.3 \%)$ & $27(62.8 \%)$ & 94 (79.7\%) & $\begin{array}{l}\text { Pass to } \\
\text { round } 2\end{array}$ \\
\hline $\begin{array}{l}T_{x} 2 \\
\text { Considering the proposed classification system in the algorithm, do you think } \\
\text { that the proposed TREATMENTS ARE APPROPRIATE for each group? }\end{array}$ & 69 (92\%) & $30(69.8 \%)$ & 99 (83.9\%) & $\begin{array}{l}\text { Pass to } \\
\text { round } 2\end{array}$ \\
\hline $\begin{array}{l}\mathrm{T}_{\mathrm{x}} 3 \\
\text { Do you think it is appropriate to schedule a follow-up visit I month after } \\
\text { treatment INITIATION for COPD? }\end{array}$ & $6 \mathrm{I}(8 \mathrm{I} .3 \%)$ & $4 \mathrm{I}(95.3 \%)$ & $102(86.4 \%)$ & Consensus \\
\hline $\begin{array}{l}T_{x} 4 \\
\text { Do you think it is appropriate to schedule FOLLOW-UP visits to monitor } \\
\text { COPD patients and their treatment every } 4 \text { to } 6 \text { months? }\end{array}$ & $59(78.7 \%)$ & $32(74.4 \%)$ & 91 (77.1\%) & $\begin{array}{l}\text { Pass to } \\
\text { round } 2\end{array}$ \\
\hline $\begin{array}{l}T_{x} 5 \\
\text { Do you think that recommendations for evaluating patients between visits } \\
\text { adequately cover the main FACTORS that should be taken into account } \\
\text { during the FOLLOW-UP of a patient with COPD? }\end{array}$ & 67 (89.3\%) & 39 (90.7\%) & $106(89.8 \%)$ & Consensus \\
\hline $\begin{array}{l}T_{x} 6 \\
\text { Do you agree with the proposed definitions for EXACERBATION SEVERITY } \\
\text { in the algorithm? }\end{array}$ & 70 (93.3\%) & 39 (90.7\%) & 109 (92.4\%) & Consensus \\
\hline $\begin{array}{l}\mathrm{T}_{\times} 7 \\
\text { Do you agree with the definition of NOT IMPROVING/NOT STABLE in the } \\
\text { algorithm? }\end{array}$ & $75(100 \%)$ & $42(97.7 \%)$ & 117 (99.2\%) & Consensus \\
\hline
\end{tabular}

(Continued) 
Table I (Continued).

\begin{tabular}{|c|c|c|c|c|}
\hline Question & $\begin{array}{l}\text { No. (\%) in } \\
\text { Agreement } \\
\text { (FDs) }\end{array}$ & $\begin{array}{l}\text { No. (\%) in } \\
\text { Agreement } \\
\text { (Pulmonologists) }\end{array}$ & $\begin{array}{l}\text { No. (\%) in } \\
\text { Agreement } \\
\text { (Overall) }\end{array}$ & $\begin{array}{l}\text { Decision } \\
\text { Taken }\end{array}$ \\
\hline $\begin{array}{l}T_{x} 8 \\
\text { Do you think the recommended ACTIONS for a patient who has NOT } \\
\text { IMPROVED/HAS NOT BEEN STABLE since the last visit are appropriate? }\end{array}$ & 74 (98.7\%) & 37 (86\%) & III (94.1\%) & Consensus \\
\hline $\begin{array}{l}T_{x} 9 \\
\text { Do you think that the recommended MODIFICATIONS to a treatment that } \\
\text { has NOT resulted in IMPROVEMENT since the last visit are appropriate? }\end{array}$ & 72 (96\%) & 34 (79.1\%) & 106 (89.8\%) & Consensus \\
\hline $\begin{array}{l}T_{x} 10 \\
\text { Do you think that the recommendation to ADD DRUGS to a dual therapy } \\
\text { regimen (multiple therapy) is appropriate? }\end{array}$ & 7I (94.7\%) & 33 (76.7\%) & 104 (88.1\%) & Consensus \\
\hline $\begin{array}{l}T_{x} I I \\
\text { Do you think that a patient with COPD prescribed DUAL THERAPY should } \\
\text { be monitored in primary care or referred to a pulmonologist? }\end{array}$ & 62 (83.1\%) & 35 (83.1\%) & 97 (82.2\%) & Consensus \\
\hline $\begin{array}{l}T_{x} / 2 \\
\text { Do you think that the recommendation to directly refer a patient with } \\
\text { COPD on MULTIPLE THERAPY to a pulmonologist is appropriate? }\end{array}$ & 40 (53.3\%) & 39 (90.7\%) & 79 (66.9\%) & $\begin{array}{l}\text { Pass to } \\
\text { round } 2\end{array}$ \\
\hline $\begin{array}{l}T_{x} 13 \\
\text { Do you think that the FOLLOW-UP RECOMMENDATIONS proposed for a } \\
\text { patient with COPD are the most appropriate? }\end{array}$ & 64 (85.3\%) & $4 I$ (95.3\%) & 105 (88.9\%) & Consensus \\
\hline $\begin{array}{l}T_{x} 14 \\
\text { Overall, do you think that the design of the PATIENT CLASSIFICATION } \\
\text { AND FOLLOW-UP section of the algorithm is clear and practical for routine } \\
\text { management in primary care? }\end{array}$ & 67 (89.3\%) & 35 (8I.4\%) & 102 (86.4\%) & Consensus \\
\hline \multicolumn{5}{|l|}{ General } \\
\hline $\begin{array}{l}\text { Finally, do you think that the ALGORITHM as a whole is functional and useful } \\
\text { for routine primary care practice? }\end{array}$ & 72 (96\%) & 38 (88.4\%) & II 10 (93.2\%) & Consensus \\
\hline
\end{tabular}

practicalities and needs behind caring for COPD patients in primary care.

In the first round of the Delphi process, $98.3 \%$ of the FDs and $81.4 \%$ of the pulmonologists agreed that the proposed algorithm constituted a clear and practical tool for the simplified management of COPD in routine primary care practice.

The algorithm as a whole was also rated as being both functional and useful by $96 \%$ of FDs and $88.4 \%$ of pulmonologists.

The resulting algorithm is based on current GOLD recommendations and is similar to previously published algorithms. ${ }^{1,3,6}$ It is, however, much simpler and more intuitive than the GOLD recommendations. It has been widely demonstrated that dyspnea rather than exacerbations is used to guide prognosis in the GOLD guidelines, even though recommendations for treatment changes are based much more on exacerbations than symptoms. In our new simplified algorithm, dyspnea is the basis for treatment modifications. Exacerbations occur in patients already on dual bronchodilator therapy, as they appear to be mainly caused by dyspnea. $^{29}$

Our algorithm differs broadly from the one in the GOLD document. The implicit classification by severity (dyspnea) leads to one unequivocal treatment option. We offer a step by step treatment, easy to understand and to follow in a real-life situation. Opposed to GOLD, we start with double bronchodilation in the case of severe dyspnea ( $\geq 2$ in the mMRC scale) because there is evidence of its superiority in almost every field (dyspnea, exercise, and pulmonary function) vs the monocomponents in these patients. Exacerbations are related to the severity of the 
Table 2 Results from the Second Round of the Delphi Process

\begin{tabular}{|c|c|c|c|c|}
\hline Question & $\begin{array}{l}\text { No. (\%) in } \\
\text { Agreement } \\
\text { (FDs) }\end{array}$ & $\begin{array}{l}\text { No. (\%) in } \\
\text { Agreement } \\
\text { (Pulmonologists) }\end{array}$ & $\begin{array}{l}\text { No. }(\%) \text { in } \\
\text { Agreement } \\
\text { (Overall) }\end{array}$ & $\begin{array}{l}\text { Decision } \\
\text { Taken }\end{array}$ \\
\hline \multicolumn{5}{|l|}{ Diagnosis } \\
\hline $\begin{array}{l}D_{x} 2 \\
\text { Do you think that the PATIENT EVALUATION section of the algorithm } \\
\text { adequately covers the main RISK FACTORS that should raise suspicion of } \\
\text { COPD? }\end{array}$ & 72 (97.3\%) & $42(100 \%)$ & 114 (98.2\%) & Consensus \\
\hline $\begin{array}{l}D_{\times} 3 \\
\text { Do you think that the algorithm adequately covers the main entities that } \\
\text { should be included in the DIFFERENTIAL DIAGNOSIS to rule out COPD? }\end{array}$ & 71 (95.9\%) & $40(95.2 \%)$ & III (95.7\%) & Consensus \\
\hline \multicolumn{5}{|l|}{ Classification and treatment } \\
\hline $\begin{array}{l}T_{x} I \\
\text { After a spirometry to confirm a diagnosis of COPD and evaluation of } \\
\text { dyspnea using the mMRC, do you think that the proposed classification } \\
\text { system is appropriate for deciding on treatment for a patient newly diagnosed } \\
\text { with COPD taking into account that the algorithm includes treatment } \\
\text { monitoring and modification recommendations? }\end{array}$ & $70(94.6 \%)$ & $38(90 \%)$ & $108(93.1 \%)$ & Consensus \\
\hline $\begin{array}{l}\mathrm{T}_{\mathrm{x}} 2 \\
\text { Considering the proposed classification system in the algorithm, do you think } \\
\text { that the new treatment proposal for a patient with newly diagnosed COPD is } \\
\text { appropriate? }\end{array}$ & 69 (93.2\%) & 37 (88.1\%) & $106(91.4 \%)$ & Consensus \\
\hline $\begin{array}{l}\mathrm{T}_{\times} 4 \\
\text { Do you think it is appropriate to schedule FOLLOW-UP visits to monitor } \\
\text { COPD patients and their treatment every } 2-6 \text { months? }\end{array}$ & $65(87.8 \%)$ & 37 (88.1\%) & $102(96.2 \%)$ & Consensus \\
\hline $\begin{array}{l}T_{x} 12 \\
\text { Do you think it is appropriate that a patient with COPD who is prescribed } \\
\text { MULTIPLE THERAPY is monitored in primary care if he/she is stable and } \\
\text { referred to a pulmonologist otherwise? }\end{array}$ & $65(87.8 \%)$ & $28(66.7 \%)$ & $93(80,2 \%)$ & Consensus \\
\hline \multicolumn{5}{|l|}{ General } \\
\hline $\begin{array}{l}\text { Overall, do you think that this new algorithm is clear and practical for routine } \\
\text { management in primary care? }\end{array}$ & $70(94.6 \%)$ & $36(85.7 \%)$ & $106(91.4 \%)$ & Consensus \\
\hline
\end{tabular}

disease, so it seems logical to us to start the inhaled steroids if you are already in double bronchodilation and still exacerbate (grade $\mathrm{C}$ in GOLD diagram is so scarce in clinical practice that our proposal did not incorporate this scenario). This approach is different from the GOLD consensus, in which you can treat a very severe patient (for example; a patient with very high dyspnea and exacerbations) with just a LAMA in the first visit. In addition, by doing a step by step approach, our proposal avoids the need of additional algorithms for subsequent visits, as GOLD does.
The simplicity of our algorithm, together with its broad acceptance by healthcare professionals directly involved in the care of patients with COPD, increases the likelihood of its uptake in primary care and pulmonology settings.

In conclusion, this study, which was structured in four phases - proposal, validation, refinement, and consensus, led to the development of a simple intuitive, functional, and useful tool for the diagnosis, treatment, and management of COPD in routine primary care settings. 


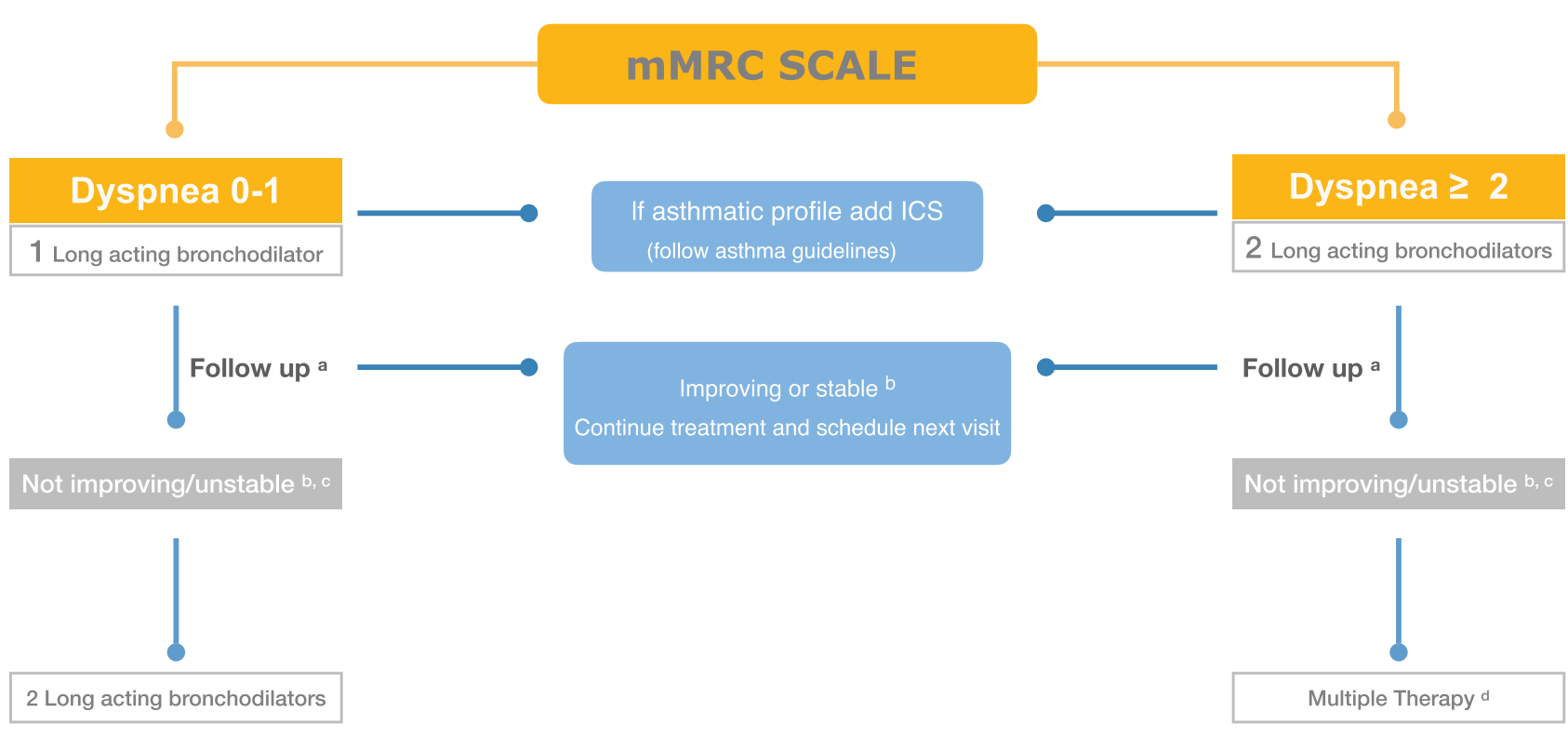

Figure 3 Final diagram of the treatment of COPD as proposed by the Delphi consensus. (A) One month after starting treatment and then every 2-6 months. Assess dyspnea (mMRC) and exacerbations. (B) Check treatment adherence and correct inhaler use, assess other comorbidities, modify treatment if necessary, and schedule next visit. (C) Dyspnea persistence or worsening and/or one severe or two moderate exacerbations. (D) Add ICS for exacerbation, SABA as rescue therapy, systemic antibiotics and/or corticosteroids for acute exacerbation, PDE4 inhibitors for chronic bronchitis and exacerbation, methylxanthines if stability is not achieved despite maximum treatment, and mucolytics/antioxidants for plentiful secretions. Refer to specialist if no improvement or unstable.

\section{Abbreviations}

COPD, chronic obstructive pulmonary disease; FDs, family doctors; ICS, inhaled corticosteroids; LABA, long-acting $\beta$-agonist; mMRC, modified Medical Research Council; SABA, short-acting $\beta$-agonist.

\section{Author Contributions}

All authors made substantial contributions to the conception and design, acquisition of data, or analysis and interpretation of data; took part in drafting the article or revising it critically for important intellectual content; agreed to submit to the current journal; gave final approval of the version to be published; and agree to be accountable for all aspects of the work.

\section{Disclosure}

Dr Enrique Mascarós reports personal fees from Esteve, GSK, Pfizer, Teva, Astra-Zeneca, Orion, BoehringerIngelheim, and Novartis, outside the submitted work. The authors report no other conflicts of interest in this work.

\section{References}

1. Miravitlles M, Sicras A, Crespo C, et al. Costs of chronic obstructive pulmonary disease in relation to compliance with guidelines: a study in the primary care setting. Ther Adv Respir Dis. 2013;7(3):139-150. doi: $10.1177 / 1753465813484080$
2. López-Campos JL, Abad Arranz M, Calero Acuña C, et al. Determinants for changing the treatment of COPD: a regression analysis from a clinical audit. Int J Chron Obstruct Pulmon Dis. 2016;2(11):1171-1178. doi:10.2147/COPD.S103614

3. The global initiative for chronic obstructive lung disease, 2020 global strategy for prevention, diagnosis and management of COPD. Available from: https://goldcopd.org/wp-content/uploads/2019/12/ GOLD-2020-FINAL-ver1.2-03Dec19_WMV.pdf.

4. Miravitlles M, Soler-Cataluña JJ, Calle M, et al. Spanish guidelines for management of chronic obstructive pulmonary disease (gesepoc) 2017. pharmacological treatment of stable phase. Arch Bronconeumol. 2017;53(6):324-335. doi:10.1016/j.arbres.2017.03.018

5. Cabrera C, Casanova C, Martín Y, et al. Agreement between a simple dyspnea-guided treatment algorithm for stable COPD and the GOLD guidelines: a pilot study. Int J Chron Obstruct Pulmon Dis. 2016;8 (11):1217-1222. doi:10.2147/COPD.S100853

6. Miravitlles M, Anzueto A. A new two-step algorithm for the treatment of COPD. Eur Respir J. 2017;49:1602200. doi:10.1183/139930 03.02200-2016

7. Wensing M, Huntink E, van Lieshout J, et al. Tailored implementation of evidence-based practice for patients with chronic diseases. PLoS One. 2014;9(7):e101981. doi:10.1371/journal. pone.0101981

8. Lundell S, Tistad M, Rehn B, Wiklund M, Holmner Å, Building WK. COPD care on shaky ground: a mixed methods study from Swedish primary care professional perspective. BMC Health Serv Res. 2017;17(1):467. doi:10.1186/s12913-017-2393-y

9. Harlander M, Barrecheguren M, Turel M, Miravitlles M. Should patients switched from $\mathrm{d}$ to $\mathrm{b}$ in the gold 2017 classification be discontinued from inhaled corticosteroids? COPD. 2017;14(5):465468. doi:10.1080/15412555.2017.1342233

10. Casas Maldonado F, Arnedillo Muñoz A, López-Campos JL, et al. Documento de recomendaciones para el diagnóstico y tratamiento de la enfermedad pulmonar obstructiva crónica en Andalucía. [Recommendations for diagnosis and treatment of Chronic Obstructive Disease in Andalusia]. 2017. Spanish. 
11. Cohen JS, Miles MC, Donohue JF, Ohar JA. Dual therapy strategies for COPD: the scientific rationale for LAMA + LABA. Int J Chron Obstruct Pulmon Dis. 2016;15(11):785-797.

12. Vogelmeier C, Worth H, Buhl R, et al. "Real-life" inhaled corticosteroid withdrawal in COPD: a subgroup analysis of DACCORD. Int J Chron Obstruct Pulmon Dis. 2017;1(12):487-494. doi:10.2147/ COPD.S125616

13. Yawn BB, Thomashaw B, Mannino DM, et al. The 2017 Update to the COPD Foundation COPD Pocket Consultant Guide. Chronic Obstr Pulm Dis. 2017;4(3):177-185. doi:10.15326/jcopdf.4.3.2017.0136

14. Rodrigo GJ, Price D, Anzueto A, et al. LABA/LAMA combinations versus LAMA monotherapy or LABA/ICS in COPD: a systematic review and meta-analysis. Int J Chron Obstruct Pulmon Dis. 2017;17 (12):907-922. doi:10.2147/COPD.S130482

15. Tariq SM, Thomas EC. Maintenance therapy in COPD: time to phase out ICS and switch to the new LAMA/LABA inhalers? Int J Chron Obstruct Pulmon Dis. 2017;23(12):1877-1882. doi:10.2147/COPD.S138006

16. Yawn BB, Thomashaw B, Mannino DM, et al. 2017 Update to the COPD foundation COPD pocket consultant guide. Chronic Obstr Pulm Dis. 2017;4(3):177-185.

17. Han MK, Quibrera PM, Carretta EE, et al., SPIROMICS investigators. Frequency of exacerbations in patients with chronic obstructive pulmonary disease: an analysis of the SPIROMICS cohort. Lancet Respir Med. 2017;5(8):619-626. doi:10.1016/S2213-2600(17)30207-2

18. Lipworth B, Jabbal S. A pragmatic approach to simplify inhaler therapy for COPD. Lancet Respir Med. 2017;5(9):679-681. doi:10.1016/S2213-2600(17)30264-3

19. Miravitlles M, Izquierdo JL, Esquinas C, et al. The variability of respiratory symptoms and associated factors in COPD. Respir Med. 2017;129:165-172. doi:10.1016/j.rmed.2017.06.017

20. Nonato NL, Díaz O, Nascimento OA, Dreyse J, Jardim JR, Lisboa C. Behavior of quality of life (SGRQ) in COPD patients according to BODE scores. Arch Bronconeumol. 2015;51(7):315-321. doi:10.1016/ j.arbres.2014.02.017

21. Vogelmeier CF, Criner GJ, Martinez FJ, et al. Strategy for the diagnosis, management, and prevention of chronic obstructive lung disease 2017 report. GOLD executive summary. Am J Respir Crit Care Med. 2017;195(5):557-582. doi:10.1164/rccm.201701-0218PP

22. Evaluation of appropriateness of inhaled corticosteroid (ICS) therapy in COPD and guidance on ICS withdrawal. Miguel RománRodríguez, Ioanna Tsiligianni, Siân Williams. Editor: Tracey Lonergan. Funding: Self-funded by IPCRG. Date published: May 2020 (2nd edition). Available from: https://www.ipcrg.org/dth6. Accessed December 03, 2020.
23. Rieger-Reyes C, García-Tirado FJ, Rubio-Galán FJ, Marín-Trigo JM. Classification of chronic obstructive pulmonary disease severity according to the new global initiative for chronic obstructive lung disease 2011 guidelines: COPD assessment test versus modified medical research council scale. Arch Bronconeumol. 2014;50 (4):129-134. doi:10.1016/j.arbres.2013.09.014

24. Linstone, Harold A., and Murray Turoff, eds. The delphi method. Reading, MA: Addison-Wesley, 1975.

25. Soler-Cataluña JJ, Alcázar-Navarrete B, Miravitlles M. The concept of control of COPD in clinical practice. Int J Chron Obstruct Pulmon Dis. 2014;(9):1397-1405.

26. Trappenburg JC, van Deventer AC, Troosters T, et al. The impact of using different symptom-based exacerbation algorithms in patients with COPD. Eur Respir J. 2011;37(5):1260-1268. doi:10.1183/ 09031936.00130910

27. Qaseem A, Wilt TJ, Weinberger SE, et al. American College of Physicians; American College of Chest Physicians; American Thoracic Society; European Respiratory Society. Diagnosis and management of stable chronic obstructive pulmonary disease: a clinical practice guideline update from the American College of Physicians, American College of Chest Physicians, American Thoracic Society, and European Respiratory Society. Ann Intern Med. 2011;155 (3):179-191.

28. Sulku J, Janson C, Melhus H, et al. A Cross-Sectional Study Assessing Appropriateness of Inhaled Corticosteroid Treatment in Primary and Secondary Care Patients with COPD in Sweden. Int $J$ Chron Obstruct Pulmon Dis. 2019;14:2451-2460. doi:10.2147/ COPD.S21874

29. Cabrera Lopez C, Casanova Macario C, Marin Trigo JM, et al. Comparison of the 2017 and 2015 global initiative for chronic obstructive lung disease reports. impact on grouping and outcomes. Am J Respir Crit Care Med. 2018;197(4):463-469. doi:10.1164/ rccm.201707-1363OC

\section{Publish your work in this journal}

The International Journal of COPD is an international, peer-reviewed journal of therapeutics and pharmacology focusing on concise rapid reporting of clinical studies and reviews in COPD. Special focus is given to the pathophysiological processes underlying the disease, intervention programs, patient focused education, and self management protocols. This journal is indexed on PubMed Central, MedLine and CAS. The manuscript management system is completely online and includes a very quick and fair peer-review system, which is all easy to use. Visit http://www.dovepress.com/testimonials.php to read real quotes from published authors 